\title{
Evaporative Flux Method of Leaf Hydraulic Conductance Estimation: Sources of Uncertainty and Reporting Format Recommendation
}

\section{Xiaoxiao Wang}

Huazhong Agriculture University https://orcid.org/0000-0002-5909-3905

Jinfang Zhao

Huazhong Agriculture University

Jianliang Huang

Huazhong Agriculture University

Shaobing Peng

Huazhong Agriculture University

Dongliang Xiong ( $\nabla$ dlxiong@mail.hzau.edu.cn )

Huazhong Agriculture University https://orcid.org/0000-0002-6332-2627

\section{Research}

Keywords: leaf hydraulic conductance (Kleaf), evaporation flux method (EFM), sample, gravity pressure, degassed water, steady identify, report format

Posted Date: July 22nd, 2021

DOI: https://doi.org/10.21203/rs.3.rs-717330/v1

License: (c) (i) This work is licensed under a Creative Commons Attribution 4.0 International License.

Read Full License 


\section{Abstract}

The accurate estimation of leaf hydraulic conductance $\left(K_{\text {leaf }}\right)$ is important for revealing leaf physiology characteristics and function. However, there are some uncertain influencing factors in $K_{\text {leaf }}$ measurement by using evaporation flux method (EFM), a widely used method. In this study, we investigated the potential impacts of plant sampling method, measurement setup, environmental factors, recording instrument, and transpiration steady status identification on $K_{\text {leaf }}$ estimation. Our results indicated that the sampling and rehydration time, the small gravity pressure on leaf, and degassing treatment had limited effects on $K_{\text {leaf }}$ values. Transpiration rate $(E)$ was significantly affected by multiple environmental factors including airflow around leaf, light intensity, and leaf temperature. $K_{\text {leaf }}$ values decreased by $40 \%$ from 1000 to $500 \mu \mathrm{mol} \mathrm{m}{ }^{-2} \mathrm{~s}^{-1}$ light intensities and by $15.1 \%$ from 27 to $37^{\circ} \mathrm{C}$. In addition, the accurate flow rate $(F)$ steady state identification and the leaf water potential measurement were important for $K_{\text {leaf }}$ estimation. Based on the analysis of influencing factors, we provided a format for reporting the details of the EFM-based $K_{\text {leaf }}$ measurement methods and metadata that future studies could interpret the results in method issue.

\section{Highlight}

The influences of measurement setup, environmental factors, and flow rate steady state identification on $K_{\text {leaf }}$ measurement were estimated and reporting format of $K_{\text {leaf }}$ were proposed.

\section{Background}

Plant hydraulic properties strongly influence photosynthesis and plant performance. At a given soil water potential, the capacity of leaves to maintain open stomata for photosynthesis depends on a plant hydraulic conductance [1]. On average, the hydraulic resistance in leaves accounts for $30 \%$ of that in whole-plant, thus leaves constitute an important bottleneck for hydraulic conductance [2]. Due to the important role of leaf hydraulic conductance $\left(K_{\text {leaf }}\right)$ in plant, $K_{\text {leaf }}$ has been extensively studied over the last decades [3-7]. The efficiency of water transport from the petiole to the sites of evaporation through the leaf tissues is quantified as $K_{\text {leaf }}$, and it is generally expressed as water transport efficiency per leaf area unit $\left(\mathrm{mmol} \mathrm{m}^{-2} \mathrm{~s}^{-1} \mathrm{MPa}^{-1}\right)$. A number of approaches have been used to estimate $K_{\text {leaf }}$ based on excised leaves, such as the evaporative flux method (EFM), the rehydration kinetics methods (RKM), the high-pressure flowmeter (HPFM), and the vacuum pump method (VPM) etc.

In all these methods, the $K_{\text {leaf }}\left(K_{\text {leaf }}=E / \Delta \mathrm{P}\right)$ is estimated by measuring the ratio of transpiration rate $(E)$ through the leaf to the driving force (water potential gradient between the petiole to evaporation sites, $\Delta \mathrm{P})$. Although many methods developed to measure $K_{\text {leaf }}$, the EFM has the advantage of mimicking the natural transpiration pathways of water movement in the leaf [5]. Furthermore, the EFM method allows other functional traits, such as carbon assimilation and stomatal conductance, to be measured simultaneously. Actually, the EFM has been used to measure stomatal conductance, by recording the air 
humidity and air temperature around the leaf during steady-state flow [8]. As the $K_{\text {leaf }}$ has also been used to explain a range of other physiological processes including photosynthesis and leaf economical spectrum $[9,10]$, simultaneous estimation of $K_{\text {leaf }}$ and other traits will provide more reliable information.

While the EFM was used in estimating $K_{\text {leaf }}$ more and more frequently, the $K_{\text {leaf }}$ values estimated by EFM from different groups are largely incomparable even for the same species (Figure S1). Great difference in $K_{\text {leaf }}$ has been found in the same ecotype Columbia of Arabidopsis thaliana. In some studies [11-13], $K_{\text {leaf }}$ is less than $10 \mathrm{mmol} \mathrm{m}^{-2} \mathrm{~s}^{-1}$, but it is much larger than $10 \mathrm{mmol} \mathrm{m}^{-2} \mathrm{~s}^{-1}$ or even more than 50 mmol m $\mathrm{m}^{-2} \mathrm{~s}^{-1}$ in other studies [14] (detail data shown in Fig.S1). Surprisingly, the huge difference in $K_{\text {leaf }}$ values estimated using EFM was even found in the same rice cultivar, Shanyou 63; the $K_{\text {leaf }}$ values reported in several studies vary greatly from $0.64 \mathrm{mmol} \mathrm{m}^{-2} \mathrm{~s}^{-1}$ to $23 \mathrm{mmol} \mathrm{m}^{-2} \mathrm{~s}^{-1}$ [15-18].

Different $K_{\text {leaf }}$ among studies may be induced by different growth environmental factors such as light, temperature, humidity during the growth of the plants. However, it seems unlike that growth conditions in these studies could have led to such huge differences in $K_{\text {leaf }}$ values [18-20]. Scoffoni et al. estimated the $K_{\text {leaf }}$ of six species of lobeliads grown in two irradiances (daily average of $300 \mathrm{vs} 800 \mu \mathrm{mol}$ photons $\mathrm{m}^{-2} \mathrm{~s}^{-1}$ ) and found the largest variation was a 2.5 -fold increase in $K_{\text {leaf }}$ of plants when they were transferred from low light to high light growth condition [20]. Alternately, the differences in $K_{\text {leaf }}$ among studies may partially be due to measurement bias and interference. However, the sources of uncertainty in using EFM have been less investigated, and, in fact, the details of the $K_{\text {leaf }}$ measurements were not available in many studies $[15,16,19,21-24]$, which did not conform to the transparent and comprehensive principles.

The lack of $K_{\text {leaf }}$ estimation and reporting format makes the full and efficient use of $K_{\text {leaf }}$ from other studies difficult. It is essential to explore the estimation and reporting formats of $K_{\text {leaf }}$ for unifying and normalizing $K_{\text {leaf }}$ data with different sources. The study aims to investigate the effects of interference factors during measurement on initial and final leaf water potential $\left(\Psi_{\text {leaf }}\right)$, flow rate/transpiration rate $(F / E)$ and hydraulic conductance $\left(K_{\text {leaf }}\right)$ and to provide the detail recommendations for EFM measurement and report.

\section{Results}

Leaf hydraulic conductance measurements were performed in rice leaves sampled at different time points to test the sampling time effects. Although the initial leaf water potential was low for the tillers which were sampled at night and rehydrated overnight in the lab, this low water potential had no influence on $K_{\text {leaf }}$. Actually, no differences in both stable $F$ and $\psi_{\text {final }}$ were found between the leaves sampled at the night before the measurement date and the leaves sampled at the early morning of the measurement date. The $\psi_{\text {initial }}$ was continuously recorded from the night before the measuring date. The results demonstrated that $\psi_{\text {initial }}$ of leaves sampled at night was consistently high within 12 hours, but 
decreased with great differences among leaves in the next day, and recutting in the morning or storage in sterile water alleviated this change tendency (Fig.S3, Fig. 1). No differences in $\Psi_{\text {initial, }}, \Psi_{\text {finall }}$, and $K_{\text {leaf }}$ estimations were observed between the leaves rehydrated in sterile water and the leaves rehydrated in non-sterile water (Fig. 1).

Equipment setting was identified between sample preparation and measurement. Firstly, we evaluated the impacts of water degassing on $K_{\text {leaf }}$ by comparing the estimated parameters of water application of degassed measurement water and those of distilled measurement water in the cylinder. Our data showed that water degassing had no influence on $E, \Psi_{\text {final, }}$, and $K_{\text {leaf }}$ estimation (Fig. 2). Next, the height of water was taken into account in the case of $K_{\text {leaf }}$ estimation using EFM, since the height pressure difference may exist between leaf and water surface in cylinder. Our results showed $2 \mathrm{~cm}$ height gradient between leaf and water surface in cylinder exhibited no effect on $K_{\text {leaf }}$ measurement (Fig. 3 ). In addition, the cylinder water evaporation without leaf under multiple conditions was quantified. The evaporation rate of cylinder water without any cover on water surface to prevent evaporation was $0.115 \times 10^{-3} \mathrm{mmol} \mathrm{s}^{-1}$. The evaporation rate was significantly declined under liquid wax addition and/or high humidity in weighting chamber (ANOVA, P < 0.001) (Fig.S2).

The effects of environmental factors including light intensity, air temperature, and the leaf surface airflow on $K_{\text {leaf }}$ estimation were investigated. $K_{\text {leaf }}$ estimated by EFM was significantly higher in $1000 \mu \mathrm{mol} \mathrm{m}^{-2}$ $\mathrm{s}^{-1}$ light intensity than in other two light intensities (500 and $1500 \mu \mathrm{mol} \mathrm{m}^{-2} \mathrm{~s}^{-1}$ ). The higher $K_{\text {leaf }}$ under $1000 \mu \mathrm{mol} \mathrm{m} \mathrm{m}^{-2} \mathrm{~s}^{-1}$ light intensity conditions might be caused by the higher transpiration rate and higher water potential. Low $K_{\text {leaf }}$ values were found under high air temperature treatments with high $\mathrm{E}$, because $\Psi_{\text {leaf }}$ was also decreased under high temperature. The airflow had the strong effects on transpiration but not on $K_{\text {leaf }}$ estimation (Table 1 ). 
Table 1

Influences of different ambient light intensity (PARa), temperatures and airflow rate on E, $\psi_{\text {final }}$ and $K_{\text {leaf }}$.

\begin{tabular}{|c|c|c|c|c|c|c|c|}
\hline Environment & & $\begin{array}{l}E\left(\mathrm{mmol} \mathrm{m} \mathrm{m}^{-2}\right. \\
\left.\mathrm{s}^{-1}\right)\end{array}$ & & $\begin{array}{l}\Psi_{\text {final }} \\
(\mathrm{MPa})\end{array}$ & & $\begin{array}{l}K_{\text {leaf }}\left(\mathrm{mmol} \mathrm{m} \mathrm{m}^{-2} \mathrm{~s}^{-1}\right. \\
\left.\mathrm{MPa}^{-1}\right)\end{array}$ & \\
\hline \multirow{3}{*}{$\begin{array}{l}\text { PARa } \\
\left(\mu \mathrm{mol} \mathrm{m}{ }^{-2} \mathrm{~s}^{-}\right. \\
\left.{ }^{1}\right)\end{array}$} & 500 & $5.68 \pm 0.147$ & \multirow[t]{3}{*}{$\star \star \star$} & $\begin{array}{l}-0.32 \pm \\
0.023\end{array}$ & \multirow[t]{3}{*}{ ns } & $16.0 \pm 1.13$ & \multirow[t]{3}{*}{ * } \\
\hline & 1000 & $8.75 \pm 0.328$ & & $\begin{array}{l}-0.31 \pm \\
0.01\end{array}$ & & $26.8 \pm 1.49$ & \\
\hline & 1500 & $9.22 \pm 0.707$ & & $\begin{array}{l}-0.38 \pm \\
0.04\end{array}$ & & $18.7 \pm 2.28$ & \\
\hline \multirow{2}{*}{$\begin{array}{l}\mathrm{T}_{\text {air }} \\
\left({ }^{\circ} \mathrm{C}\right)\end{array}$} & 37 & $10.00 \pm 0.361$ & \multirow[t]{2}{*}{$\star \star \star ~$} & $\begin{array}{l}-0.36 \pm \\
0.01\end{array}$ & \multirow[t]{2}{*}{ ns } & $23.0 \pm 1.03$ & * \\
\hline & 27 & $7.01 \pm 0.308$ & & $\begin{array}{l}-0.29 \pm \\
0.03\end{array}$ & & $27.1 \pm 1.01$ & \\
\hline \multirow{2}{*}{$\begin{array}{l}\text { Airflow } \\
\left(\mathrm{m} \mathrm{s}^{-1}\right)\end{array}$} & 1.0 & $5.14 \pm 0.111$ & \multirow[t]{2}{*}{ * } & $\begin{array}{l}-0.28 \pm \\
0.03\end{array}$ & \multirow[t]{2}{*}{ ns } & $20.9 \pm 2.91$ & ns \\
\hline & 0 & $4.66 \pm 0.157$ & & $\begin{array}{l}-0.34 \pm \\
0.04\end{array}$ & & $16.6 \pm 3.02$ & \\
\hline
\end{tabular}

After completing the continuous recording of the cylinder water weight loss, raw flow data were obtained. Identification of $\mathrm{F}$ steady state is an important section in the next because the $K_{\text {leaf }}$ calculation is strongly dependent on the stabilization of water flow rate through the leaf. However, our data indicated that in some leaves, $F$ changed largely in oscillatory and falling $F$-time curve, and they didn't achieve the steady standard (Fig. 4). Only 2/3 measurement possessed the continuous and steady water flow in the end (Fig. 4 \& raw supplement data of flow rate). The stabilization of $F$ was further confirmed by the estimated transpiration rate of the leaf water using the gas exchange system $(S 4, S 5)$, and the $E$ values from two recording systems were only consistent in camphor leaves (Fig. 5). Importantly, the variation of water potential greatly affected $K_{\text {leaf }}$. At a given $E$ (averaged to $8.7 \mathrm{mmol} \mathrm{m}^{-2} \mathrm{~s}^{-1}$ ), $K_{\text {leaf }}$ was largely decreased (up to 3 folds) with the decrease in $\psi_{\text {leaf }}$ especially within the range of $-0.17 \sim-0.45 \mathrm{MPa}$, which related to the inverse function relation between them (Fig. 6). Hence, the effect of equilibration time on water potential was evaluated (Fig.S7). The $\psi_{\text {leaf }}$ in leaves acclimated both in dark and in light $\left(1000 \mu \mathrm{mol} \mathrm{m}^{-2}\right.$ $\mathrm{s}^{-1}$ ) in advance was decreased after long-time (60 min and $150 \mathrm{~min}$ ) equilibration. Conservatively, $10 \mathrm{~min}$ to $1 \mathrm{~h}$ equilibration time was proper for $\Psi_{\text {leaf }}$ measurement.

Finally, we proposed a reporting format for leaf hydraulic conductance measured by EFM to improve reuse and reanalysis valuable data. Not only the steady parameters but also the raw data of $F$ or $E$ relative to time should be conserved and provided to meet the needs for identifying flow rate stabilization. Moreover, airflow, temperature and light intensity also should be recorded (supplement excel). 


\section{Discussion}

Since the $K_{\text {leaf }}$ is calculated by the ratio of water flow rate to water potential gradient driving water movement across the leaf in EFM, here we evaluated the potential uncertainty factors in measuring $F$ and the leaf water potential and the responses of these two parameters to environmental factors. The results indicated that leaf water potential and $F$ were potentially influenced by environmental factors and the criterion for determining stabilization. Our investigation suggested that the dramatic difference in $K_{\text {leaf }}$ across previous studies might be attributed to methodological artifacts and incomplete reporting details of $K_{\text {leaf }}$ measurement.

\section{Influences of sample harvest and storage time on $\mathrm{K}_{\text {leaf }}$}

Although the field material sampling at the night before measurement date and rehydrating overnight in the lab are common practice in previous studies [5, 24-27], to the best of our knowledges, few studies have investigated the impacts of sampling time on $K_{\text {leaf }}$ estimation. The tension in xylem created by transpiration driver for gas exchange, but the excessive tension in the daytime poses the inherent risk for xylem cavitation, thus substantially reducing the hydraulic conductivity of plants $[28,29]$. However, no differences in $K_{\text {leaf }}$ between the leaves sampled at night and the leaves sampled in the morning was observed in this study. Rehydration overnight was projected to refill cavitated xylem conduits and restore the lost water in tissues caused by transpiration [30]. In contrast, our data indicated that the water potential of overnight rehydrated leaves was lower than that of the morning sampled leaves (Fig. 1). The $\Psi_{\text {leaf }}$ of the leaves sampled at night and rehydrated for 1 hour was as high as that of the leaves sampled in the early morning, which excluded the influence of plant hydraulic diurnal variance. One reason for low $\Psi_{\text {initial }}$ may lie in that the xylem at cut site might be blocked by mechanical wound secreta such as callose, suberin, lignin, chitinase, and various phenolics [31-33]. Another reason may lie in that cell wall integrity is damaged [34], and sucrose is accumulated outside the cut [35], thus accelerating microbe attack and the water uptake pathway blockage. Indeed, the $\psi_{\text {leaf }}$ of the overnight rehydrated leaves was increased quickly after recutting (Fig.S3), which might be attributed to the relatively high $\psi_{\text {initial }}$ and reversible outside-xylem dehydration ${ }^{[36]}$. Further efforts are needed to identify the types of microbes and/or the components the blockage.

\section{Effects of degassing and gravity pressure on $\mathrm{K}_{\text {leaf }}$}

Since water transport in plants occurs under tension, and the air-seeding and its expansion in water may create air-vapor embolisms, thus blocking water transport. To avoid embolisms, the degassed water is used for $K_{\text {leaf }}$ measurement in previous studies ${ }^{[37,38]}$, however, little literature on the effects of nondegassing on measurement is available. The comparison results of $K_{\text {leaf }}$ measured using ultrapure water and degassed ultrapure water indicated that degassing had little influence on $K_{\text {leaf }}$ values, which might be due to the fact that leaf selectively absorbed water rather than bubbles. Unfortunately, no direct evidence has been detected in this study or provided in previous studies. The EFM follows the natural transpiration- 
driven water movement pathway in leaves. The application of this method requires that water enters the leaf through internal transpiration driving rather than via external water gravity pressure caused by lower position of leaves than the water meniscus. Furthermore, assuming that a $100 \mathrm{~cm}^{2}$ leaf with $10 \mathrm{mmol} \mathrm{m}^{-}$ ${ }^{2} \mathrm{~s}^{-1} \mathrm{E}$ was measured for 1 hour, $6.48 \mathrm{~g}$ water would be consumed, and $5 \mathrm{~cm}^{2}$ water surface height would be lowered about $1 \mathrm{~cm}$. However, the relative position difference between leaves and water source was largely ignored in previous studies using EFM for $K_{\text {leaf }}$ measurement. In this study, when the leaf was placed below, as high as, or above the meniscus of water in the cylinder, the estimated $K_{\text {leaf }}$ values were no difference. The possible reason was that only $0.196 \mathrm{~Pa}$ extra gravity pressure was added. The result indicated that the small height difference between leaves and water source was permitable for $K_{\text {leaf }}$ measurement.

\section{Potential errors in flow stabilization identification and water potential measurement}

Although $E$ is one of two key parameters for $K_{\text {leaf }}$ calculation, few studies have reported the dynamics of the $F$ over the measurements. When the leaves are exposed to irradiance, the leaf stomata will open slowly, and $F$ will increase smoothly and reach stabilization within $20-60$ minutes ${ }^{[26,37,39]}$. F is considered as stable when the $F$ variation was $<5 \%$ over $3-10$ min ${ }^{[26,37,40]}$. However, these reported criteria were not suitable for our $K_{\text {leaf }}$ measurement because long internal such as $30 \mathrm{~s}$ was applied in these studies. Stricter criteria ( $P>0.001,15 \mathrm{~min})$ for identifying $F$ stabilization were applied in this study. Unexpectedly, we found that the $E$ was dramatically oscillated and even reduced after a short-term increase over the measurement of some leaves (Fig. 4). Stomatal oscillations have frequently been observed in previous studies, indicating the hydraulic mismatch between the transpiration rate and the xylem water supply rate ${ }^{[41]}$. The simultaneous estimation of liquid flow rate and transpiration rate supported this mismatching hypothesis (Fig.S5), and the oscillation was slight in low transpiration condition (such as low light condition). $F$ decline after reaching a peak might result from disruption of ionic homeostasis, which might be further attributed to the wide use of deionized water in EFM. Bundle sheath cells permeability have been reported to be related to $x y l e m ~ p H$, ionic concentration and component ${ }^{[42-44]}$. Since the $E$ is highly dynamic over the measurement, and the $F$ steady status identification directly determine $K_{\text {leaf }}$ calculation, reporting the details of $F$ estimation method as well as the raw data of $F$ could will be helpful for researchers to interpret the results and conduct meta-analysis.

In addition to the effect of $F$ value, the $K_{\text {leaf }}$ was also strongly affected by leaf water potential. EFM is mainly used for estimating maximum $K_{\text {leaf, }}$ and in maximum $K_{\text {leaf }}$ estimation, $\psi_{\text {final }}$ is usually high. In this study, the $\Psi_{\text {final }}$ was higher than $-0.4 \mathrm{MPa}$. Water potential is typically measured using pressure chamber technique and the methodological artifacts have been discussed for decades ${ }^{[45-49]}$. For instance, Levin [46] reported that the different measurement values were obtained by different operators. In addition, the leaf water was suggested to be equilibrated in bags before the sample measurement. However, the effects of equilibration time have rarely been reported in literature. In this study, the leaves acclimated to dark and light had different water potential, but both of them achieved water equilibrium between 
symplast and apoplast rapidly in bag. When the equilibration time in bag was longer than $2.5 \mathrm{~h}$, the water loss through bag would significantly change $\psi_{\text {leaf. }}$. Further works on improving the accuracy of water potential estimation are needed.

Interestingly, the significant correlation between liquid flow and gas flow was only observed in camphor with small leaves (Fig. 5). The non-correlation between two-phase $F$ in rice might result from the high heterogeneity in its leaves. For example, leaf nitrogen content, photosynthesis, and stomata varied longitudinally (from leaf base to tip) ${ }^{[50]}$. This result reminds us of the cautious use of in situ $K_{\text {leaf }}$ measurement with photosynthetic instrument, as widely used method.

\section{Conclusion}

This study described the processes of the $K_{\text {leaf }}$ estimation using EFM technique in detail from sample preparation to transpiration steady status identification. We found that environmental factors (including light intensity, measurement temperature, and airflow around leaf), flow rate steady status identifications, and $\psi_{\text {final }}$ significantly affected $E$ or $K_{\text {leaf }}$. Therefore, it is highly recommended to provide detailed environmental settings, to preserve the raw data of $F$ dynamics, to increase the water potential measurement accuracy. In light of the rapid development of database and meta-analysis, the uniform measurement and data preservation would be necessary. However, lack of unified criteria makes full and efficient use of these data difficult. This study recommends a table-like ${ }^{[51,52]}$ format convenient for $K_{\text {leaf }}$ data measurement and storage. This format can not only provide information for $K_{\text {leaf }}$ determination by EFM, but also improve the availability of $K_{\text {leaf }}$ data.

\section{Methods}

\section{Plant materials}

All the materials grew outdoors in Huazhong Agricultural University, Wuhan, China $\left(114^{\circ} 22^{\prime} \mathrm{E}, 30^{\circ} 29^{\prime} \mathrm{N}\right)$. A rice (Oryza sativa L.) cultivar Huanghuazhan ( $\mathrm{HHZ}$ ) growing in paddy field between 50 70 days after transplant was selected. All the materials were well watered and fertilized, free of diseases, pests, and weeds. Meanwhile, camphor (Cinnamomum camphora L.) grew in campus was investigated to test the relationships of two transpiration values obtained respectively by gas exchange instrument and balance, because camphor has relatively small leaves which can be fully covered in gas exchange chamber.

\section{Harvest time and sample storage}

Rice tillers were cut off in the paddy field under water in the early morning (between 5:30 am and 6:00 am) or previous day night (between 18:30 pm and 19:00 am). The fresh cut of tiller was soaked in degassed pure water, and leaves were covered with black plastic bags. The samples collected at night were conserved in ordinary ultrapure water and sterile ultrapure water, and half the tillers were randomly selected and recut in the morning to test the effect of blockage at the cut surface (Fig.S3). Longer than 
$0.5 \mathrm{~m}$ camphor branches were sampled in the early morning and conserved in ordinary ultrapure water. It took 10 to $15 \mathrm{~min}$ to transfer the samples to the laboratory. Branches and tillers were recut under pure water. Their cut ends were soaked in water, and other parts were covered with bags for at least 1 hour.

\section{Equipment settings}

Leaf hydraulic conductance ( $\left.K_{\text {leaf }}\right)$ was determined using evaporative flux method (EFM) reported previously ${ }^{[5,37]}$. To reduce system error, the water evaporation in the graduated cylinder under multiple conditions was quantified as blank control. The system transpiration was measured under the following four conditions: the water without any addition, water with addition of liquid wax, the balance chamber with high humidity by putting wet tissue papers, and the combination of liquid wax addition and high humidity in the balance chamber. The combination was adopted in the subsequent leaf experiments due to its superior capacity to prevent water loss. In order to avoid ion deposition in leaf, ultra-pure water rather than ionic solution was adopted ${ }^{[53,54]}$. Ultra-pure water was vacuumed for 8 hours to remove bubbles or directly stored overnight for measuring.

One end of low-resistance transparent tube (inner diameter $=2 \mathrm{~mm}$, Oupli campany, Shanghai, China) filled water was connected to the graduated cylinder with water on a balance $( \pm 0.01 \mathrm{mg}$; Mettler MS205DU, Mettler-Toledo GmbH, Greifensee, Switzerland). Finally, water volume in cylinder was adjusted to ensure that leaves were placed $2 \mathrm{~cm}$ below, $2 \mathrm{~cm}$ above, or as high as the meniscus of the water in the cylinder.

\section{Changes in environmental factors}

After sample preparation and system setting, three environmental factors - light intensity, air temperature, and airflow around leaf - were individually changed. The environment conditions were as follows: the temperature was set as $37 \pm 1^{\circ} \mathrm{C}$ or $27 \pm 1^{\circ} \mathrm{C}$; the photosynthetic photon flux density (PPFD) at leaf surface was set as 500,1000 , or $1500 \mu \mathrm{mol} \mathrm{m}^{-2} \mathrm{~s}^{-1}$; and the relative humidity was set as $50 \%$.

\section{$K_{\text {leaf }}$ measurement}

The newly- and fully-expanded target leaves with $2 \mathrm{~cm}$ sheathes or petioles were cut from tiller under airless distilled water. Leaf sheathes of rice leaves or the petioles of camphor leaves were connected to the water pipe using a hose tape and cork to achieve seamless connection between the petiole and tube. Leaf was lifted higher than water surface to detect whether bubbles occurred in the connection. After leaf was placed on fish line net, leaf surface was wiped with tissue paper and irradiated by lamp (600W, Weichuang Company, Wuhan, China). A box fan (Comfort Zone 20 Inch Box Fan, the factory Depot Advantages, Inc, USA) was used to minimize the boundary resistance (wind speed marked on the fan was $1 \mathrm{~m} \mathrm{~s}^{-1}$ or $\left.0 \mathrm{~m} \mathrm{~s}^{-1}\right)$. At the same time, water weight in the graduated cylinder and flow rate $(F)$ were recorded every 3 seconds. 
The water flow rate into the leaves was recorded until it was stable for a period of time. The detail identification of steady state was described in statistical analysis section below. The temperature of the blade middle was determined as leaf temperature by thermocouple (XimaAS877, Wanchuang electronic products Co., Ltd, Dongguan, China). Afterwards, leaf area (LA) and final leaf water potential () were measured. $K_{\text {leaf }}$ was calculated according to the following formula:

$$
K_{\text {leaf }}=E /\left(\left(0-\Psi_{\text {final }}\right)\right)
$$

Where $E$ referred to evaporation rate, and it was calculated as water flow rate $(F)$ divided by leaf area (LA). All the $K_{\text {leaf }}$ values were normalized into those at $25^{\circ} \mathrm{C}$ considering that water viscosity varied with temperature ${ }^{[55]}$. The measurements were performed from 8:00 am to 18:00 pm since there was no correlation between measuring time and $K_{\text {leaf }}$ or $E$ (data not shown).

\section{Leaf water potentials}

Upper and lower leaves adjacent to the target leaf used for hydraulic conductance measurement were cut from the tiller before $K_{\text {leaf }}$ measurement, quickly put in an exhaled double-layer zip-lock bag, and placed in a foam box for water equilibration. Subsequently, leaf initial water potential ( $\left.\psi_{\text {intial }}\right)$ was detected in pressure chamber (PMS Instrument Company, Albany, OR, USA). Constant slow pressurization rate was maintained during measurement. After flow measurement, the finial leaf water potential $\left(\psi_{\text {final }}\right)$ was determined, as described above. In addition, the water equilibration time of leaves in foam box were divided into 10,20,30,60,90, 120, 150, and180 min. Since there was no difference in $\psi$ under 10 60 min equilibration, we selected 30 min equilibration time in this study.

\section{Liquid flow and gas flow comparison}

In order to test the consistency of liquid flow rate and gas flow rate obtained by balance and near infrared gas analyzer LI-6800 portable photosynthesis system (LI-COR Inc., Lincoln, NE, USA), leaf was quickly clamped by $6 * 6 \mathrm{~cm}$ transparent chamber (LI-6800-13, LI-COR Inc., Lincoln, NE, USA) in the middle of rice leaf or the whole leaf blade of the camphor after being put on net. The chamber environment was as coincident with ambient environment as possible. Auto-log was conducted with 30 -second interval until a steady state was reached.

\section{Statistical analysis}

As the flow data was typically dynamic, the judgment on whether the flow rate has stabilized is challenge. An effective method to restrict segment lengths of given flow data is to explicitly allow high variance of segments, and segment length restriction was achieved via the break-point penalty parameter P in ' $d p s e g$ ' package. In our analysis, high $\mathrm{P}$ value will allow high variance of the individual segments to produce long segments. F - time curve was segmented according to P-value, and the obtained segments were marked with different color. Different segments separated by a few outliers produced within 1 min were regarded 
as one segment (Fig.4). The time corresponding to the last segment was required to be longer than 15 min, and the t-test P-value of the curve slope corresponding to the last 15 min (about 300 points) was required to be larger than 0.001 .

One-way analysis of variation (ANOVA) and multiple comparisons (least significant ranges, 'agricolae' package) were conducted at level of 0.05 . The correlation between traits was fitted using ' $g$ gpmisc' package. All figures were plotted using 'tidyverse' package. All of the statistical analyses were performed in $\mathrm{R}$ version 3.6.1 (https://cran.r-project.org).

\section{Declarations}

\section{Supplementary information}

The following supplementary data are available at Plant Method online or github (https://github.com/wangxiaoxiao123/Wang-et-al2021Additional-file).

Additional file 1.pdf. supplementary figures

Fig. S1. A literature survey on methods used in measuring $K_{\text {leaf }}$.

Fig. S2. The blank test for system errors.

Fig. S3. Influences of sample storage time and recutting actions on leaf water potential.

Fig. S4. Transpiration rate measured by Licor6800 and balance simultaneously.

Fig. S5. Mismatch between vapor flux and liquid flow of the leaves.

Fig. S6. Dynamic E over time in two ambient temperatures.

Fig. S7. Effects of equilibration time on leaf water potential estimation.

Additional file 2.xlsx. All the tidy data used in the main figures

Additional file 3.xlsx. All the raw flow data used in the in the main figures

\section{Acknowledgements}

Not applicable.

\section{Authors' contributions}

Xiaoxiao Wang: Methodology, Visualization, Resources, Data Curation, Writing - Original Draft Jinfang Zhao: Resources, Methodology Jianliang Huang: Supervision Shaobing Peng: Project administration Dongliang Xiong: Funding acquisition, Conceptualization, Writing - Review \& Editing 


\section{Funding}

This study was supported by the National Natural Science Foundation (No. 32022060).

\section{Availability of data and materials}

The datasets supporting the findings of this study are available within the paper and within its supplementary materials published online.

\section{Ethics approval and consent to participate}

Not applicable.

\section{Consent for publication}

Not applicable.

\section{Competing interests}

The authors declare that they have no competing interests.

\section{References}

1. Scoffoni, C., Chatelet, D. S., Pasquet-kok, J. et al. Hydraulic basis for the evolution of photosynthetic productivity. Nature Plants. 2016; 2: 16072.

2. Sack, L. \& Holbrook, N. M. Leaf hydraulics. Annu Rev Plant Biol. 2006; 57: 361-381.

3. Brodribb, T. J. \& Holbrook, N. M. Stomatal closure during leaf dehydration, correlation with other leaf physiological traits. Plant Physiol. 2003; 132: 2166-2173.

4. Blackman, C. J. \& Brodribb, T. J. Two measures of leaf capacitance: insights into the water transport pathway and hydraulic conductance in leaves. Funct Plant Biol. 2011; 38: 118-126.

5. Sack, L., Melcher, P. J., Zwieniecki, M. A. \& Holbrook, N. M. The hydraulic conductance of the angiosperm leaf lamina: a comparison of three measurement methods. J Exp Bot. 2002; 53: 21772184.

6. Nardini, A., Tyree, M. T. \& Salleo, S. Xylem cavitation in the leaf of Prunus laurocerasus and its impact on leaf hydraulics. Plant Physiol. 2001; 125: 1700-1709.

7. Cochard, H., Venisse, J. S., Barigah, T. S. et al. Putative role of aquaporins in variable hydraulic conductance of leaves in response to light. Plant Physiol. 2007; 143: 122-133.

8. Guyot, G., Scoffoni, C. \& Sack, L. Combined impacts of irradiance and dehydration on leaf hydraulic conductance: insights into vulnerability and stomatal control. Plant Cell Environ. 2012; 35: 857-871.

9. Xiong, D. \& Flexas, J. Leaf economics spectrum in rice: Leaf anatomical, biochemical and physiological trait trade-offs. J Exp Bot. 2018; 69: 5599-5609. 
10. Wright, I. J., Reich, P. B., Westoby, M. et al. The worldwide leaf economics spectrum. Nature. 2004; 428: 821-827.

11. Sade, N., Shatil-Cohen, A., Attia, Z. et al. The role of plasma membrane aquaporins in regulating the bundle sheath-mesophyll continuum and leaf hydraulics. Plant Physiol. 2014; 166: 1609-1620.

12. Pantin, F., Monnet, F., Jannaud, D. et al. The dual effect of abscisic acid on stomata. New Phytol. 2013; 197: 65-72.

13. Scoffoni, C., Albuquerque, C., Cochard, H. et al. The causes of leaf hydraulic vulnerability and its influence on gas exchange in Arabidopsis thaliana. Plant Physiol. 2018; 178: 1584-1601.

14. Attia, Z., Dalla, A. \& Moshelion, M. Vascular bundle sheath and mesophyll cells modulate leaf water balance in response to chitin. Plant J. 2020; 101: 1368-1377.

15. Yang, Y., Zhang, Q., Huang, G., Peng, S. \& Li, Y. Temperature responses of photosynthesis and leaf hydraulic conductance in rice and wheat. Plant Cell Environ. 2020; 43: 1437-1451.

16. Huang, G., Zhang, Q., Wei, X., Peng, S. \& Li, Y. Nitrogen can alleviate the inhibition of photosynthesis caused by high temperature stress under both steady-state and flecked irradiance. Front in Plant Sci. 2017; 8: 945.

17. Xiong, D., Yu, T., Zhang, T. et al. Leaf hydraulic conductance is coordinated with leaf morphoanatomical traits and nitrogen status in the genus Oryza. J Exp Bot. 2015; 66: 741-748.

18. Ding, L., Li, Y., Gao, L. et al. Aquaporin Expression and Water Transport Pathways inside Leaves Are Affected by Nitrogen Supply through Transpiration in Rice Plants. International Journal of Molecular Sciences. 2018; 19: 256.

19. Locke, A. M. \& Ort, D. R. Leaf hydraulic conductance declines in coordination with photosynthesis, transpiration and leaf water status as soybean leaves age regardless of soil moisture. J Exp Bot. 2014; 65: 6617-6627.

20. Scoffoni, C., Kunkle, J., Pasquet-Kok, J. et al. Light-induced plasticity in leaf hydraulics, venation, anatomy, and gas exchange in ecologically diverse Hawaiian lobeliads. New Phytol. 2015; 207: 4358.

21. Ounapuu-Pikas, E. \& Sellin, A. Plasticity and light sensitivity of leaf hydraulic conductance to fast changes in irradiance in common hazel (Corylus avellana L.). Plant Sci. 2020; 290: 110299.

22. Scoffoni, C., Rawls, M., McKown, A., Cochard, H. \& Sack, L. Decline of leaf hydraulic conductance with dehydration: relationship to leaf size and venation architecture. Plant Physiol. 2011; 156: 832843.

23. Trifilo, P., Petruzzellis, F., Abate, E. \& Nardini, A. The extra-vascular water pathway regulates dynamic leaf hydraulic decline and recovery in Populus nigra. Physiol Plantarum. 2021; 172: 29-40.

24. Xiong, D., Douthe, C. \& Flexas, J. Differential coordination of stomatal conductance, mesophyll conductance, and leaf hydraulic conductance in response to changing light across species. Plant Cell Environ. 2018; 41: 436-450. 
25. Sack, L., Cowan, P. D. \& Holbrook, N. M. The major veins of mesomorphic leaves revisited: tests for conductive overload in Acer saccharum (Aceraceae) and Quercus rubra (Fagaceae). Am J Bot. 2003; 90: 32-39.

26. Brocious, C. A. \& Hacke, U. G. Stomatal conductance scales with petiole xylem traits in Populus genotypes. Funct Plant Biol. 2016; 43: 553-562.

27. Wu, T., Tissue, D. T., Li, X. et al. Long-term effects of 7-year warming experiment in the field on leaf hydraulic and economic traits of subtropical tree species. Globe Change Biology. 2020; 26: 71447157.

28. Stiller, V., Lafitte, H. R. \& Sperry, J. S. Hydraulic properties of rice and the response of gas exchange to water stress. Plant Physiol. 2003; 132: 1698-1706.

29. Locke, A. M. \& Ort, D. R. Diurnal depression in leaf hydraulic conductance at ambient and elevated $\left[\mathrm{CO}_{2}\right]$ reveals anisohydric water management in field-grown soybean and possible involvement of aquaporins. Environ Exp Bot. 2015; 116: 39-46.

30. Stiller, V., Sperry, J. S. \& Lafitte, R. Embolized conduits of rice (Oryza sativa, Poaceae) refill despite negative xylem pressure. Am J Bot. 2005; 92: 1970-1974.

31. Savatin, D. V., Gramegna, G., Modesti, V. \& Cervone, F. Wounding in the plant tissue: the defense of a dangerous passage. Front in Plant Sci. 2014; 5: 470.

32. Jacobs, A. K., Lipka, V., Burton, R. A. et al. An Arabidopsis Callose Synthase, GSL5, Is Required for Wound and Papillary Callose Formation. The Plant Cell. 2003; 15: 2503-2513.

33. Clarke, H. R. G., Lawrence, S. D. J., Flaskerud , Korhnak, T. E., Gordon, M. P. \& Davis, J. M. Chitinase accumulates systemically in wounded poplar trees. . Physiol Plantarum. 1998; 103: 154-161.

34. Bellincampi, D., Cervone, F. \& Lionetti, V. Plant cell wall dynamics and wall-related susceptibility in plant-pathogen interactions. Front in Plant Sci. 2014; 5

35. Heil, M. Nightshade Wound Secretion: The World's Simplest Extrafloral Nectar? Trends Plant Sci. 2016; 21: 637-638.

36. Scoffoni, C., Albuquerque, C., Brodersen, C. et al. Outside-xylem vulnerability, not xylem embolism, controls leaf hydraulic decline during dehydration. Plant Physiol. 2017; 173: 1197-1210.

37. Sack, L. \& Scoffoni, C. Measurement of leaf hydraulic conductance and stomatal conductance and their responses to irradiance and dehydration using the evaporative flux method (EFM). J Visual Exp. 2012; 70: e4179.

38. Fu, X., Meinzer, F. C., Woodruff, D. R. et al. Coordination and trade-offs between leaf and stem hydraulic traits and stomatal regulation along a spectrum of isohydry to anisohydry. Plant Cell Environ. 2019; 42: 2245-2258.

39. Liu, H., Taylor, S. H., Xu, Q. et al. Life history is a key factor explaining functional trait diversity among subtropical grasses, and its influence differs between $C_{3}$ and $C_{4}$ species. J Exp Bot. 2019; 70: 15671580. 
40. Brodribb, T. J., Feild, T. S. \& Jordan, G. J. Leaf maximum photosynthetic rate and venation are linked by hydraulics. Plant Physiol. 2007; 144: 1890-1898.

41. Farquhar, G. D. \& Cowan, I. R. Oscillations in stomatal conductance: the influence of environmental gain. Plant Physiol. 1974; 54: 769-772.

42. Geilfus, C. M. The pH of the Apoplast: Dynamic Factor with Functional Impact Under Stress. Molecular Plant. 2017; 10: 1371-1386.

43. Grunwald, Y., Wigoda, N., Sade, N. et al. Arabidopsis leaf hydraulic conductance is regulated by xylem sap $\mathrm{pH}$, controlled, in turn, by a P-type $\mathrm{H}(+)$-ATPase of vascular bundle sheath cells. Plant J. 2021; 106: 301-313.

44. Secchi, F., Pagliarani, C., Cavalletto, S. et al. Chemical inhibition of xylem cellular activity impedes the removal of drought-induced embolisms in poplar stems - new insights from micro-CT analysis. New Phytol. 2021; 229: 820-830.

45. Turner, N. C. Measurement of plant water status by the pressure chamber technique. Irrigation Science. 1988;

46. Levin, A. D. Re-evaluating pressure chamber methods of water status determination in field-grown grapevine (Vitis spp.). Agricultural Water Management. 2019; 221: 422-429.

47. Hochberg, U. Facilitating protocols while maintaining accuracy in grapevine pressure chamber measurements- comments on Levin 2019. Agricultural Water Management. 2020; 227

48. Boyer, J. S. Isopiestic technique: measurement of accurate leaf water potentials. Science. 1966; 154: 1459-1460.

49. Scholander, P. F., Hammel, H. T. \& Bradstreet, E. D., Hemmingsen, E. A. . Sap pressure in vascular plants. Science. 1965; 148: 339-346.

50. Xiong, D., Yu, T., Liu, X. et al. Heterogeneity of photosynthesis within leaves is associated with alteration of leaf structural features and leaf $\mathrm{N}$ content per leaf area in rice. Funct Plant Biol. 2015; 42: 687-696.

51. Ely, K. S., Rogers, A., Agarwal, D. A., Ainsworth, E. A. \& Yang, D. A reporting format for leaf-level gas exchange data and metadata. Ecological Informatics. 2021; 61: 101232.

52. Kattge, J., Bönisch, G., Díaz, S. et al. TRY plant trait database - enhanced coverage and open access. Glob Change Biol. 2019; 26: 119-188.

53. Gasco, A., Nardini, A., Gortan, E. \& Salleo, S. Ion-mediated increase in the hydraulic conductivity of Laurel stems: role of pits and consequences for the impact of cavitation on water transport. Plant Cell Environ. 2006; 29: 1946-1955.

54. Hu, Y. \& Schmidhalter, U. Spatial distributions and net deposition rates of mineral elements in the elongating wheat (Triticum aestivumL.) leaf under saline soil conditions. Planta. 1998; 204: $212-219$.

55. Yang, S. \& Tyree, M. T. Hydraulic resistance in Acer saccharum shoots and its influence on leaf water potential and transpiration. Tree Physiol. 1993; 12: 231-242. 

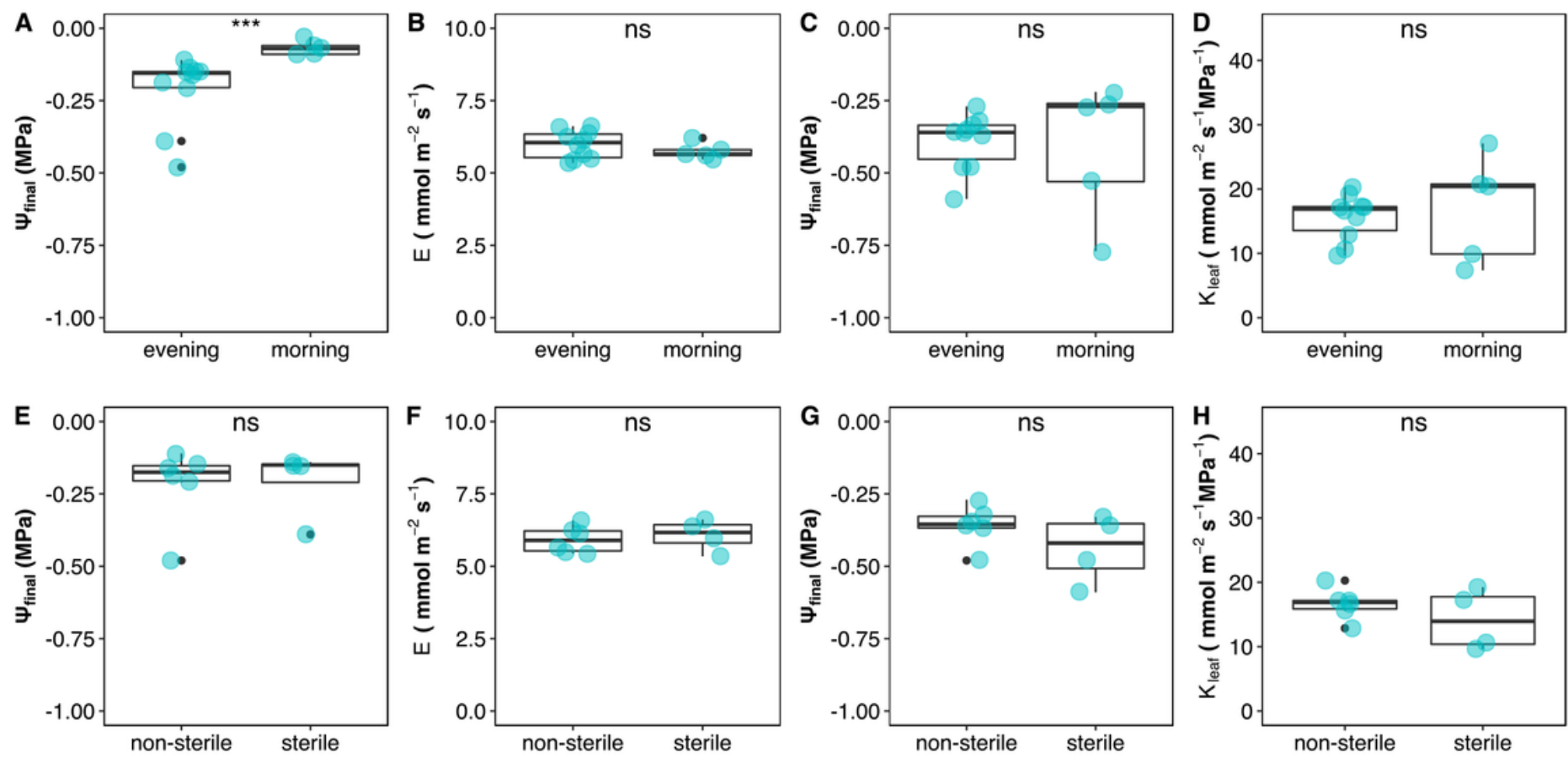

Figure 1

Influences of different sampling time on initial water potential (A), transpiration rate (B), Kleaf (C), and final water potential (D). Influences of sterile water and non-sterile water storage on initial water potential $(E)$, transpiration rate $E(F)$, Kleaf $(G)$, and final water potential $(H)$ of evening sampled leaves.
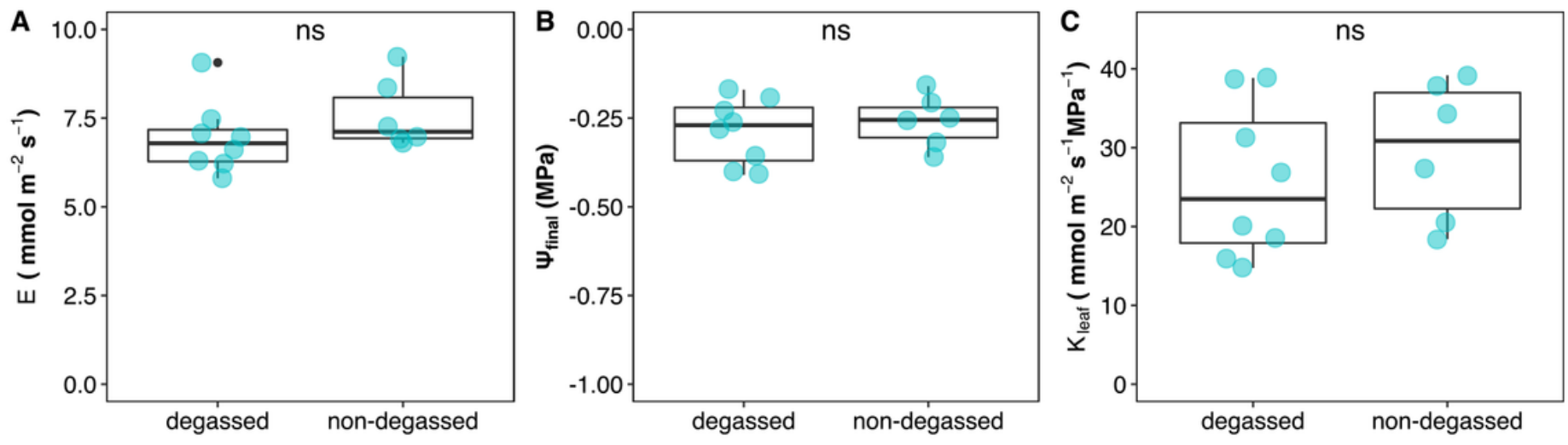

\section{Figure 2}

Influences of degassing or non-degassing measurement water on transpiration rate $E(A)$, Kleaf (B), and final water potential $\Psi$ final (C). 

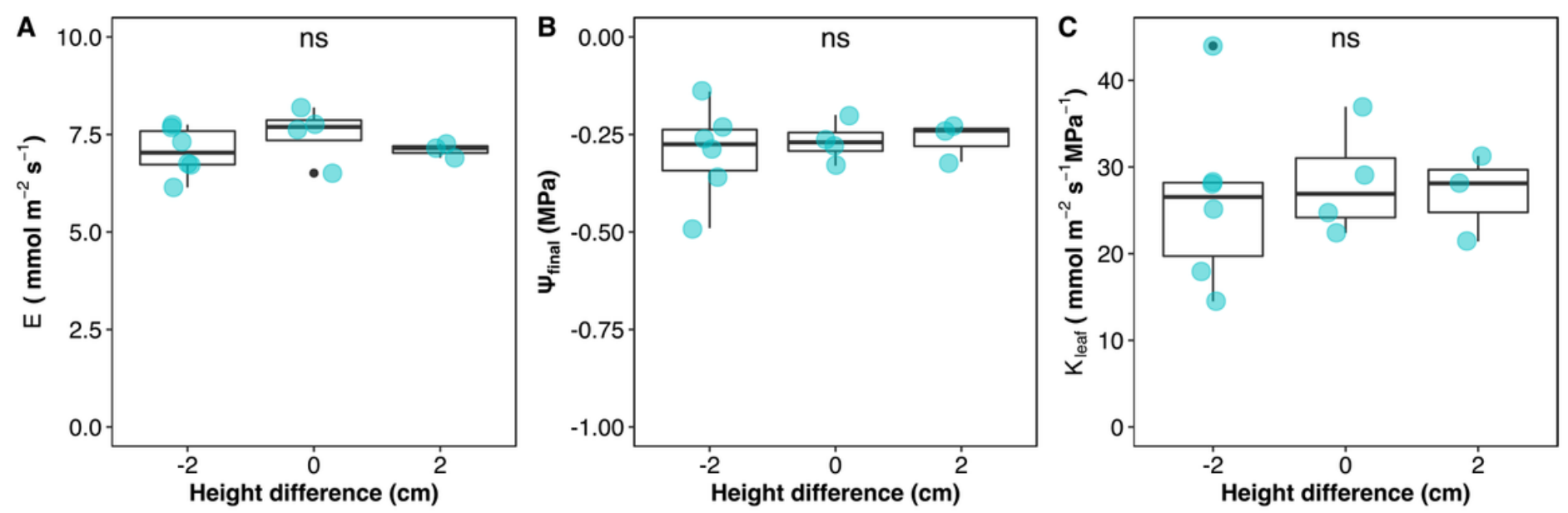

Figure 3

Influences of height differences between leaf and water source on transpiration rate $E(A)$, Kleaf (B), and final water potential $\Psi$ final (C). 0 indicates same height level between leaf and water surface; -2 indicates that water surfaceis $2 \mathrm{~cm}$ lower than leaf; 2 indicates that water surface is $2 \mathrm{~cm}$ higher than leaf. 


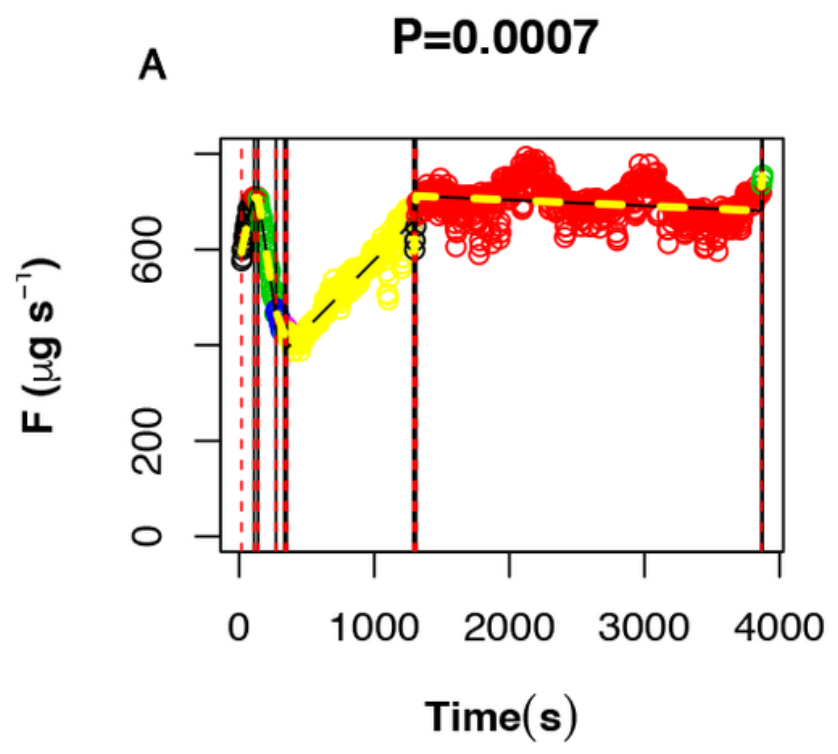

B $\quad P<2 e-16$

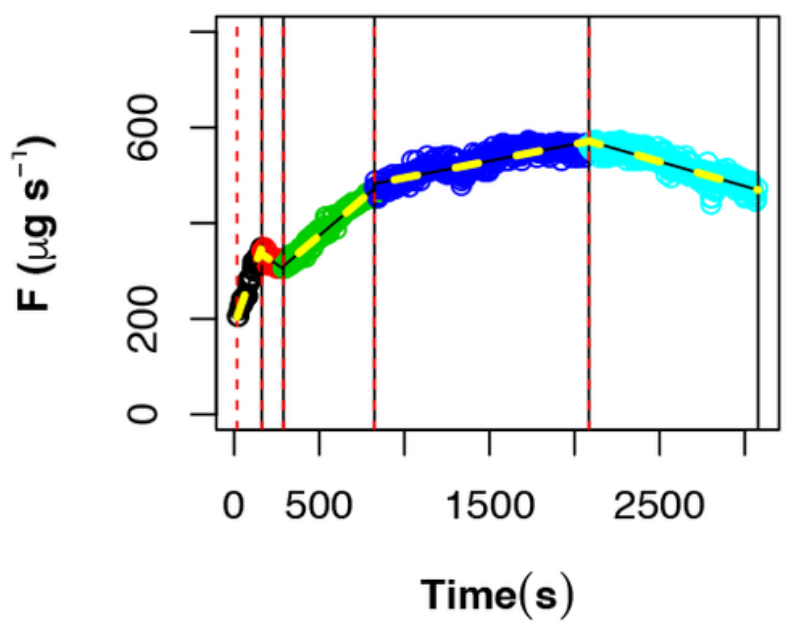

C $\quad<15 \mathrm{~min}$

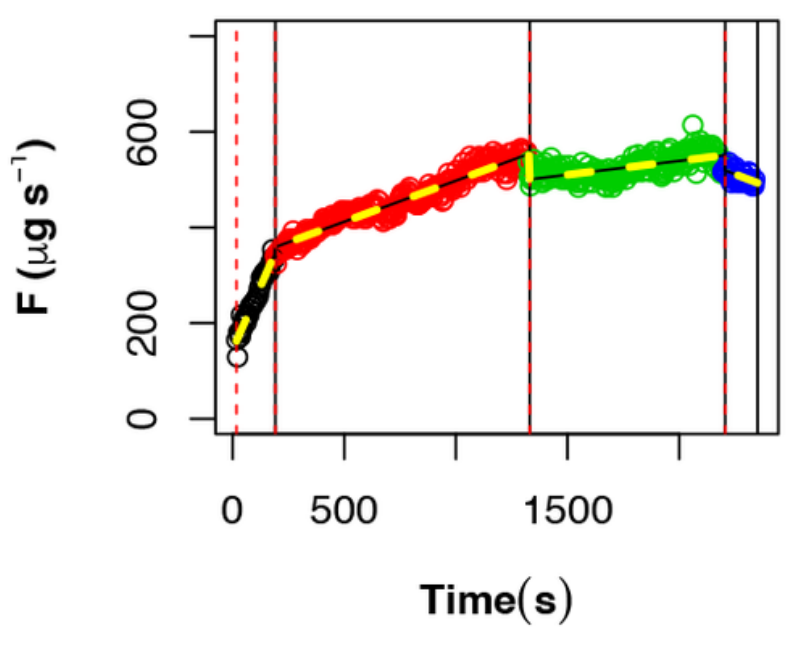

D $\quad P=0.052$

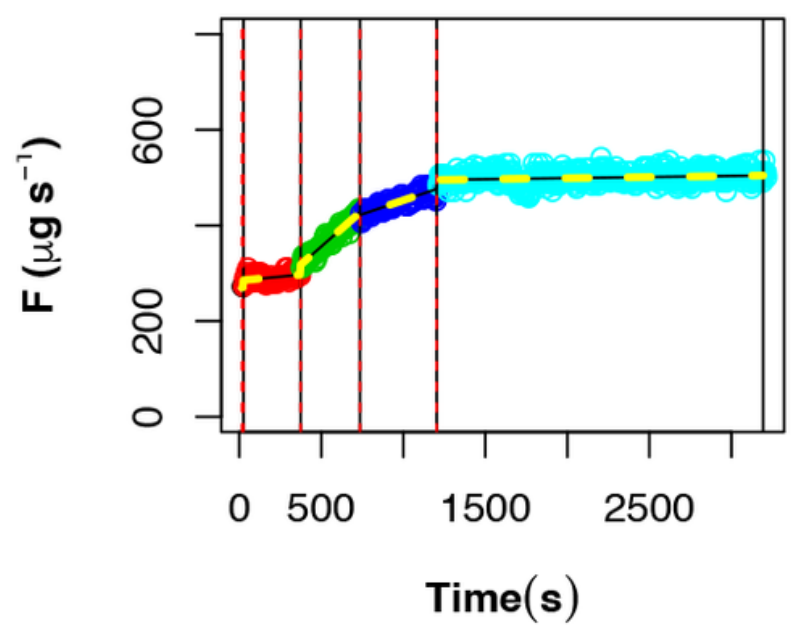

Figure 4

Fitting and segmentation results of 4 typical flow rate curves over measuring time. (A-B) Non-steady curves whose last segment slope was not equal to zero. (C) Non-steady curve whose measurement time corresponding to the last segment was less than $15 \mathrm{~min}$.(D) Steady curve. P represents the P-value of the curve in the last 15 minutes of the last segment. 


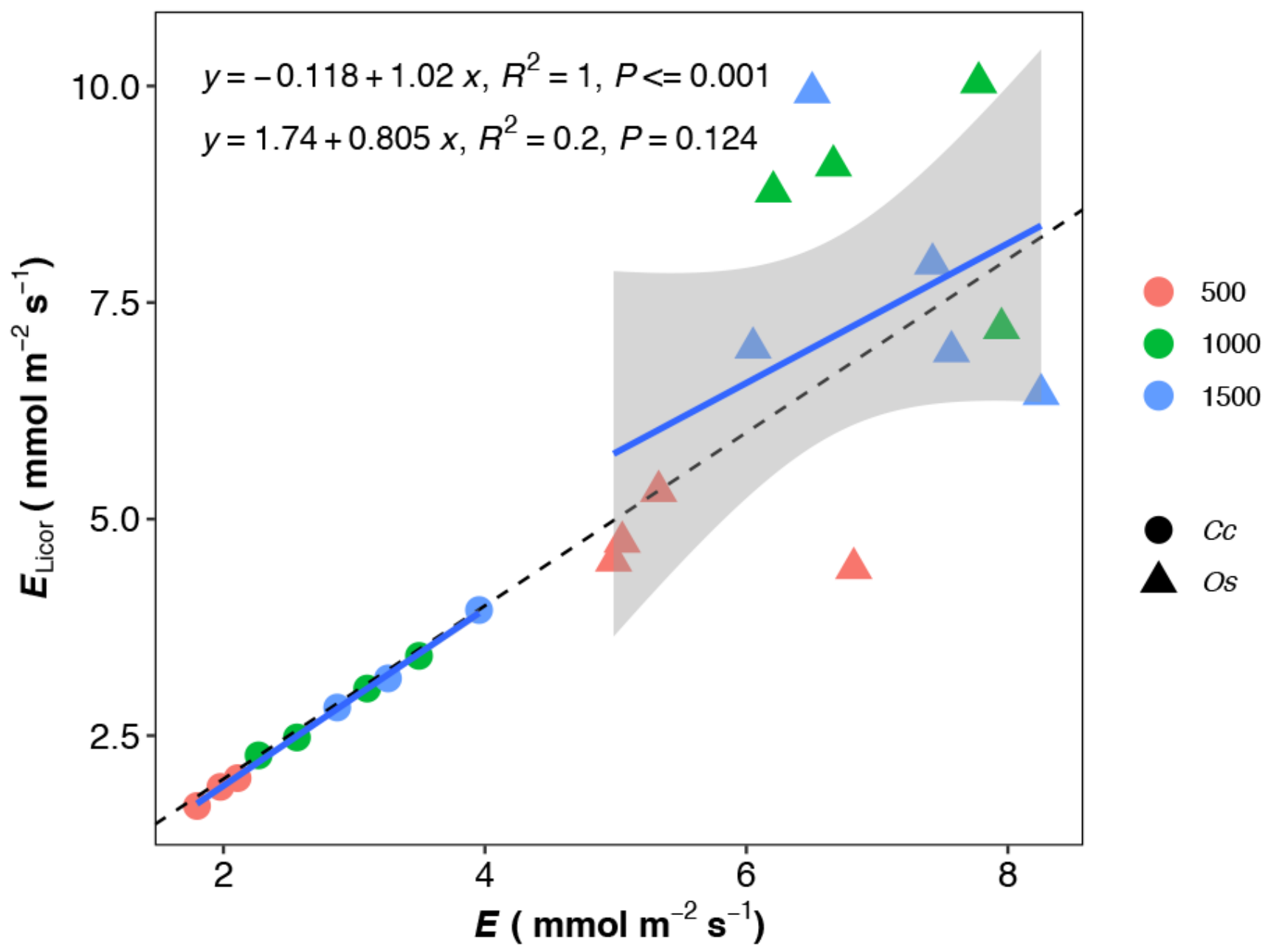

Figure 5

Correlation of E measured by Licor6800 and by balance in rice (Os, triangle) and camphor (Cc, circle). The fitted equations and their $p$-values for camphor and rice are presented in the upper left of the figure. 


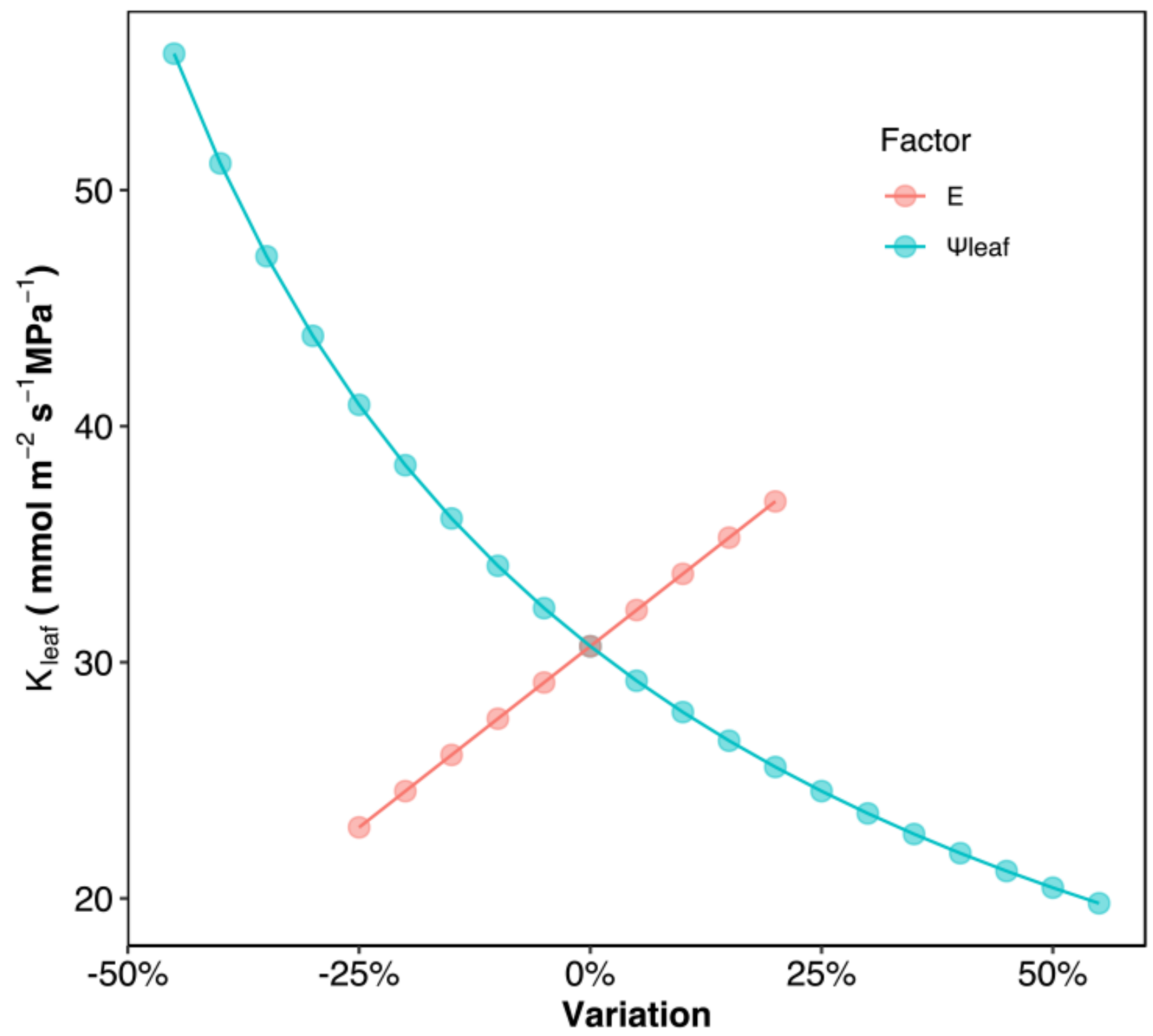

Figure 6

Sensitivity analysis of the influences of water potential ( $\Psi$ leaf) and transpiration rate $(E)$ on Kleaf. $x$-axis $0 \%$ represents mean value of Kleaf of pot-grown rice measured under $1000 \mu \mathrm{mol} \mathrm{m}-2 \mathrm{~s}-1$ light intensity.

\section{Supplementary Files}

This is a list of supplementary files associated with this preprint. Click to download.

- Additionalfile1.pdf

- Additionalfile2.xlsx 
- Additionalfile3.xIsx

Page 21/21 